\title{
Cruising for better air quality: Australian clean air submissions, issues, and recommendations
}

\author{
Angela T. Ragusa ${ }^{1,}{ }^{*}$, and Andrea Crampton ${ }^{2}$ \\ ${ }^{1}$ School of Humanities and Social Sciences, Charles Sturt U niversity, A lbury, NSW 2640, A ustralia \\ ${ }^{2}$ School of Biomedical Sciences, Charles Sturt University, A Ibury, N SW 2640, A ustralia
}

\begin{abstract}
Clean air remains an elusive and inequitable human right. Air pollution unnecessarily increases morbidity, mortality rates, and environmental degradation globally. This paper presents results from a content analysis of all ( $n=133$ ) submissions to the $2019 \mathrm{~N}$ ew South Wales Government call for public feedback to its 'Clean Air' issues and action priorities. Findings show stakeholder agreement that air pollution's regulation and measurement are problematic. Issue framing divulged stakeholder agendas, particularly for shipping industries, highlighted inconsistencies in government and industry regulations, and revealed mistrust and issue partiality. Science literacy, proximity to pollution source, socioeconomic status, and pollution visibility affected issue descriptions and recommendations. Cruise ships in Sydney Harbour received disproportionately high focus relative to their contribution to the shipping industry's contribution to local air pollution. Government and health body submissions proposed public education, awareness raising, and personal action as key steps to avoid emission exposure. We argue such 'deficit theory' approaches are inadequate in light of international research evidencing pollution visibility and personal perception poorly reflect scientific air quality measures. To surpass A ustralian NIMBY approaches to air pollution, we propose adopting European international legislative reform to equitably enforce clean air 'rights' and actions across industries, governments, and communities, irrespective of stakeholder priorities.
\end{abstract}

\section{Introduction and literature review}

Goffman's [1] classical 'frame analysis' theory informs exploring how the air pollution 'issues' and 'recommendations' presented in public submissions to the Australian New South Wales (NSW) state government's 'Clean Air' actions/priorities consultation paper are presented. Social contexts govern how information is presented, which affects its content and interpretation [1]. 'Framing' is a useful multidisciplinarily concept to explore social context and research how information is used or understood [2], particularly when used alongside 'agenda setting'. A genda-setting helps reveal how social context is affected by individual and institutional priorities that shape public knowledge and information representation $[3,4]$. We use both of these concepts to investigate Clean A ir submission foci and content discussed in this paper.

Globally, air pollution is an environmental contributor to millions of humans' premature death $[5,6]$, 4 million globally in 2015 alone [6]. A ir pollution affects developing and developed countries [7]. Sulphur dioxide $\left(\mathrm{SO}_{2}\right)$ is one of the most toxic chemicals threatening human health [8]. In 2019, Australia's National Environmental Protection Council proposed changing national standards for ozone, nitrogen dioxide, and $\mathrm{SO}_{2}$ as evidence showed increased mortality and morbidity risks occur at exposure levels lower than the current 1998 standards allow [9]. Although the 2025 changes exclude particulate matter (PM), the most significant change halves $\mathrm{SO}_{2}$ maximum concentration levels (1 hour $=0.2 \mathrm{ppm}$ to $0.1 \mathrm{ppm}, 1$ day $=0.08 \mathrm{ppm}$ to $0.02 \mathrm{ppm}$ ) [9]. Global research documents air pollution and climate change are related. Only concerted European U nion (EU) legislative and energy policy reform that incorporates environmental protection into fuel and transport activities decrease key air pollutants, particularly $\mathrm{SO}_{2}$ [10]. This paper discusses air pollution specifically related to shipping and the associated human and environmental health implications.

Australian air quality regulation is complex. Regulation relies on ambient air sampled over time for selected pollutants. Measures often fail to sufficiently detect risks for those nearest pollution sources [11]. Ship exhaust specifically contributed $1.9 \%$ PM 2.5 in greater Sydney and $9.4 \%$ in port communities, rates that demonstrably affect human health and are responsible for $\sim 220$ years of life lost when local respiratory-related deaths attributed to ship exhaust exposure are considered [12]. Differences in socioeconomic air pollution exposure are affected not merely by 'individual' protective actions (i.e. 'staying indoors') in Europe, but by legislation. "European citizens can claim their right to clean air and the agricultural sector has to support the targets under the directive" [10, p.57]. In A ustralia, government and industries' inconsistent management and regulation of air

* Corresponding author: aragusa@csu.edu.au 
pollution coexists with increased mortality rates and few legislated individual health 'rights'.

The shipping industry is a major producer of PM [12], largely derived from sulphur (S) in fuel [13], and exacerbates air pollution. Internationally, air pollution disproportionately affects low socioeconomic groups because they are nearer to pollution sources $[14,11,15]$. This is true in Australia, except for NSW ports where median suburban houses around Port Botany and White Bay are \$1.4M - \$1.7M [16]. In Sydney, unfettered cruise ship industry growth (with the 250 ship visits in 2015 projected to increase by $85 \%$ in 2025 [17]) makes air pollution from smokestacks visible to wealthy residents. Ship exhaust exposure alone accounted for $\sim 220$ years of life lost in respiratory-related deaths in Sydney [12]. If berthed ships used low (S) fuels ( $\leq 0.1 \%$ PM 2.5 ), a $25 \%$ PM 2.5 ship emission reduction and 390 life year gain for residents, extended to 920 years if the fuel restriction area was extended to $300 \mathrm{~km}$ radius of Sydney, could be gained over 20 years [12]. A ustralian changes implemented by January, 2020, under the International Convention for the Prevention of Pollution from Ships (MARPOL) [18], however, retain allowance of $\leq 0.5 \% \mathrm{~S}$ fuel. Coupled with increased passenger and cargo ships since the 2010/2011 analysis and $\leq 0.5 \%$ S recommendation [12], this will perpetuate Australian mortalities and public health burdens from shippingrelated industries.

Australian's Environmental Protection A gency (EPA) supported national $\leq 3.5 \% \mathrm{~S}$ levels, despite NSW EPA's recommendation to enforce $\leq 0.1 \% \mathrm{~S}$ for cruise ships in Sydney Harbour by 2016, a change towards reducing PM 2.5 emissions by $70 \%$ and aligning with European, A merican, and Chinese regulations for ship-to-shore power or burning $\leq 0.1 \% \mathrm{~S}$ fuel. Changes made to waters under NSW's control responded to White Bay residents' health concerns about cruise terminals and only noted urban health impacts from NSW ports; "Shipping emissions from Port Jackson, Port Botany, Newcastle Port and Port Kembla impact on population centres in Sydney, Newcastle and Wollongong" [17, p.4]. Under the heading 'potential impacts of not taking action', state government stated, "Not effecting this commitment would result in ongoing and increasing health impacts for residents in the affected communities" [17, p.5]. With lower $\mathrm{S}$ requirements for cruise ships only mandatory when docked in Sydney Harbour, lower socioeconomic NSW ports (Port Kembler, Port Eden, Newcastle) had fewer restrictions until the Federal Government voided state-based regulations in January 2016 to align with international maritime regulations of $\leq 0.5 \% \mathrm{~S}$ outside emission control areas requiring $\leq 0.1 \% \mathrm{~S}$, although no $\leq 0.1 \% \mathrm{~S}$ areas exist in Australia [19]. Federal legislation was amended to uphold NSW legislation capping cruise ships berthed in Sydney Harbour to $\leq 0.1 \% \mathrm{~S}$ fuel or alternatives, effective December 2016. Nevertheless, cruise ships may revert to $\leq 3.5 \%$ S until 2020 , then $\leq 0.5 \% \mathrm{~S}$ an hour before departure and upon port entry, only changing fuel an hour before berthing, thus air polluting even in Sydney Harbour. Cruise ships comprised $28 \%$ of Sydney Harbour ship visits in 2017/2018. Their emission focus stems from residential proximity $(50 \mathrm{~m})$ to cruise terminals. Government and industry focus on cruise ship emissions in Sydney Harbour, compared with non-passenger ports like Port Botany, only $12 \mathrm{~km}$ from the CBD and $\leq 1 \mathrm{~km}$ from residential areas, thus illustrates residents' impact.

The principle deterrent of $\mathrm{S}$ restriction to the shipping industry is increased fuel cost. This competes with increased PM 2.5 human health costs to government. Framed economically, NSW EPA [17] estimated changing emissions from $\leq 3.5 \% \mathrm{~S}$ to $\leq 0.1 \% \mathrm{~S}$ incurred a $70 \%$ (\$1.6M) cruise ship fuel cost increase for 2017 Sydney Harbour berthing that reduced PM 2.5 by $70 \%$, yielding \$5.7M 2017 health cost savings from cruise ship emissions in Sydney Harbour alone. Forecasting failed to extend to the broader shipping industry or beyond Sydney which allows higher emissions $(\leq 0.5 \% \mathrm{~S})$ under the incoming 2020 changes [19]. Globally, $\leq 0.5 \%$ S ship emissions will contribute to $250 \mathrm{k}$ deaths and $6.4 \mathrm{M}$ cases of childhood asthma annually, the majority in African, A sian, and South American coastal communities [20]. Progressing equity in clean air 'rights' thus is a topic requiring urgent, concerted non-partisan research.

\section{Methods}

In October 2016, the Office of Environment and Heritage (OEH) called for written public submissions by 20 J anuary 2017 to its co-authored (with NSW EPA) 'Clean Air for NSW Consultation Paper', advising, "Y our submissions will lay the foundation for the NSW Clean Air Summit to be held in Sydney within six months...setting the priority actions to be developed and longer term directions for NSW air quality management to 2027" [21]. Submissions were asked to comment if the government proposed "the right directions and the right actions" [21] by addressing 4 questions: A re the actions proposed in this Clean Air for NSW Consultation Paper the right actions to improve air quality?; A re there other issues and actions that Clean Air for NSW should cover?; How do you want to be informed about and involved in improving air quality?; Do you have any other comments or ideas on improving air quality in NSW?

All submissions are publicly available on the EPA's website which advises, "steps have been taken to remove the personal information of authors and any potentially defamatory comments" [22]. This paper uses deidentified data codes for 'individual' submissions' directly cited and 'real' names of authors contributing in a professional capacity.

Content analysis [23] permitted answering two research questions: What stakeholders contributed submissions to the Clean Air for NSW Consultation Paper and what key issues did they identify? Does stakeholder-type affect issue discussion of shipping? If yes, how so? All $(n=133)$ submissions were read and coded to identify air pollution source discussed. Saturation [24] was achieved with 8 manifest issue categories presented in Table 1, whereby if creating additional codes is redundant, then the coding framework is sufficient [25]. Data was entered into Excel and frequencies run. Submissions mentioning 'shipping' 
$(n=25)$ were re-read and one removed since 'shipping' appeared in a table without discussion. Manifest and latent coding [26] used cross-coder reliability measures to facilitate accuracy and validity [27], with framing and agenda-setting theory informing the content analysis [28].

\section{Results and discussion}

Key issues by stakeholder-type for all $(n=133)$ submissions appear in Table 1.

Table 1. Air pollution manifest issues by stakeholder.

\begin{tabular}{|c|c|c|}
\hline & $\begin{array}{l}\text { Stakeholder-type }(\%) \\
1=\text { Individual, } 2=\text { Community, } \\
3=\text { Isovernment, } 4=\text { Industry, } \\
5=\text { Professional Body }\end{array}$ & $\begin{array}{l}\text { \% Total } \\
\text { Issues }\end{array}$ \\
\hline $\begin{array}{l}\text { Agriculture } \\
\text { Biomass } \\
\text { burning } \\
\text { Woodheat, } \\
\text { Forestry } \\
\text { Hazard- } \\
\text { reduction }\end{array}$ & $\begin{array}{l}1=5 \%, 3=8 \%, 4=13 \%, 5=6 \% \\
1=46 \%, 2=56 \%, 3=67 \% \\
4=44 \%, 5=88 \%\end{array}$ & $\begin{array}{c}6 \%(n=8) \\
54 \%(n=72)\end{array}$ \\
\hline $\begin{array}{l}\text { Energy } \\
\text { Production - } \\
\text { Oil, Gas, Coal }\end{array}$ & $\begin{array}{l}1=10 \%, 2=56 \%, 3=42 \%, 4=26 \% \\
5=65 \%\end{array}$ & $29 \%(n=38)$ \\
\hline $\begin{array}{l}\text { Manufacturing } \\
\text { Mining }\end{array}$ & $\begin{array}{l}1=3 \%, 2=6 \%, 3=8 \&, 4=4 \%, 5=18 \% \\
1=13 \%, 2=44 \%, 3=33 \%, 4=17 \% \\
5=53 \%\end{array}$ & $\begin{array}{r}6 \%(n=8) \\
25 \%(n=33)\end{array}$ \\
\hline $\begin{array}{l}\text { Shipping - } \\
\text { Merchant, } \\
\text { Tourism }\end{array}$ & $\begin{array}{l}1=19 \%, 2=6 \%, 3=25 \%, 4=22 \% \\
5=24 \%\end{array}$ & $19 \%(n=25)$ \\
\hline $\begin{array}{l}\text { Transportation- } \\
\text { Air, Train, Auto } \\
\text { None }\end{array}$ & $\begin{array}{l}-1=37 \%, 2=61 \%, 3=75 \%, 4=70 \%, \\
5=71 \% \\
1=10 \%, 4=4 \%, 5=6 \%\end{array}$ & $53 \%(n=71)$ \\
\hline
\end{tabular}

Manifest coding suggested stakeholder-type affected shipping submissions' issues. Two 2 manifest codes (1=data/monitoring ineffectiveness/compliance and 2=regulation inadequacy/inconsistency) categorised all issues, irrespective of stakeholder-type, suggesting broad convergence around air pollution issue management/actions. Stakeholder agenda shaped how content was framed. Three latent content codes (government mistrust; regulatory, exposure, and risk inequity; issue partiality) reflected issue diversity by stakeholder-type.

\subsection{Community $(n=3)$}

All 3 Community submissions identified shipping emissions' absence in the paper and recommended shipto-shore power. W est Protects Rozelle [22, p.3] included White Bay cruise ships and generally discussed ship emissions" $\leq \mathrm{PM}_{2.5}$, "which are carcinogenic, cause respiratory problems, heart disease and other health problems", citing European analyses. Newcastle's submission had 2 'community' and 2 'industry' representatives. Both noted shipping's absence, plus tourism emissions' omission, and regulation slowness or inadequacies, requesting NSW exceed national or international standards to advocate "much more emphasis on public health" [22, p.2]. The second community representative listed "reducing industry emissions" [22, p.2] as the most relevant action and mandating high quality shipping fuel in port if unconnected to power. Industry representatives framed industry emission reduction priorities as "a little narrow in focus" since "significant industries such as agriculture and transport are not addressed" $[22, p .4]$ and cited lack of regional centre focus.

\subsection{Professional body $(n=2)$}

Both Professional Body submissions were from medicine. Doctors for the Environment (DEA) noted state governments' loss of jurisdiction over shipping emissions and the industry's small $\mathrm{PM}_{2.5}$ contribution to air pollution yet significant $S$ contribution. DEA noted the cruise ship regulation discussed despite most ships being containers, bulk carriers, oil tankers, etc. and called for greater inclusivity. Although named DEA, recommendations were framed by those offering greatest human, not environmental, health. For shipping, this was low $S$ fuel $300 \mathrm{~km}$ from port (to add 920 life-years to humans over 20 years) and ship-to-shore power at berth. Describing increased adenocarcinoma, a lung cancer significantly affecting non-smokers with $15 \%$ patientsurvival rates, the second submission co-authored by the Peter $\mathrm{MacC}$ allum Cancer Centre (PMCC) and Lung Foundation Australia evidenced Australia's lack of legislative protection, national policy dilution by States/Territories, and standards de-emphasis of public health (as national deaths from air pollution increased $68 \%$ between 2005-2010, countering most OCED countries' experience of reduced mortality from air pollution). Inaccurate data from air quality monitors far from pollution sources and allowance of carcinogenic diesel-fuelled products banned in Europe and America prompted PMCC $[22$, p.11] to argue "raising public awareness through education is vital to success". Framing shipping's deregulation as having public health consequences, cancer-prevention and air quality improvement evidenced need for legislative regulation [22, p.10]:

Shipping is a major part of the A ustralian economy and generates substantial emissions...carried into the airsheds of major urban population centres including the capital cities of Perth, M elbourne, Sydney and Brisbane. Ships generally use residue oil (RO) as fuel. The higher the sulphur content used in RO, the bigger the health impact. Ships in the Baltic Sea, North Sea, EU ports and Californian coast burn a lower sulphur content RO due to restrictions. Australia does not have these same restrictions. Ships often carry more than one type of fuel, and use the substantially cheaper high sulphur content fuel whilst in A ustralian waters generating a toxic mix of particles, NOx and SOx that can be advected over coastal population centres.

Industry's political strength, however, surpasses that of citizens to lobby governments, particularly in a nation characterised as apathetic [29-30] where public health aims are subordinate to their cost. 
Medicine's long-documented individualistic focus [31] manifested in submissions framing health a personal responsibility. This is consistent with mental and physical health research and compounded by findings that personal health perception/behaviours may, or may not, reflect scientific realities [31-34]. Hence, PMCC's [22, p.10] suggestion, "increased awareness will enable the public to take appropriate actions to reduce their personal exposure and lobby for changes in clean air policy and legislature" bellies evidenced gaps between individual environmental knowledge and action that deficit theory critics use to refute advocating 'more' knowledge for problem abatement [35-36]. Psychological research shows increased information and feeling 'overwhelmed' by knowledge heightens apathy and inaction [37]. PM CC [22, p.10] concluding, "raising public awareness through targeted, best practice public health education is the most important and achievable of the mitigation measures canvassed" reflects medicine's broader frame of individualism that may dilute the air quality improvement strategies and priorities other stakeholders promoted.

\subsection{Individuals $(n=11)$}

Although one Individual proffered broader solutions to 'incentivise' pollution reduction (i.e. create 'clean-air zones') and two discussed multiple issues, $82 \%$ reduced air pollution priorities to only White Bay cruise ships. Individuals detailed international cruise ship regulations not enacted in Australia; 64\% suggested 'plugging in' at shore, $27 \%$ wanted Australian fuel standards to mirror A merica/Europe, and suggested cruise ship levies or terminal relocation. Where Industry, Community and Professional Bodies used frames surpassing their personal interests, individuals framed issues on par with regional councils using a 'NIMBY' (not-in-my-backyard) lens. Emotive residents described, "the outrageous volumes of carcinogenic toxins spewed into Sydney's air from cruise ships...the air is so bad [blocked out by EPA] with his heart problems [he] must stay inside for the rest of summer" [22, ID3]. Individuals framed health as subject to the powerful cruise industry and government inaction. Proclivity for prioritising cruise ships extended beyond Individuals; $61 \% \quad(n=14)$ of all submissions noted pollution from increased cruise ship activity in Sydney terminals, irrespective of stakeholdertype, making it the most frequent shipping issue despite its noted absence in the paper. Scientific research evidences although air pollution from all shipping is significant, it represents $\leq 10 \%$ of air pollution in Sydney's most adversely affected locations [12]. This reveals issue bias. In 2017/2018, 6225 commercial vessels visited 6 NSW ports, with only 352 visits to Sydney by cruise ships [18]. Framing cruise ship emissions' as a major pollutant affecting local health likely reflects pollution visibility and proximity to residences more than empirical data. This framing also existed in 2 of the 3 Government submissions and supports research showing air pollution visibility affects issue awareness [38]. A wareness enhances beliefs of adverse health effects that A merican air quality measures show may be no worse or better than elsewhere [32]. Perceptions are socio-culturally valuable, yet unreliable air quality predictors. Four Individuals focused on public health issues. Consistent with Professional Body, Government, and Industry, air quality data, type, and monitor location were challenged. Whereas Industry focused on data compliance requirements, Individuals used data to advocate for improved public health and regulation/planning:

Approved development needs to reflect the air quality data and at this point of time, there is no data. The achievement of trust between the regulators and the community is currently problematic. NSW Planning has shown that it is not trusted by the community through its approval processes. The Government's response to cruise ships at W hite Bay led by Ports NSW has failed to instil any confidence in this arm of Government...planning authorities have been totally silent on air quality in the vicinity of major transport facilities and roads. The growth of shipping ports...displays total ignorance of the effects of air pollution...caused by the operation of those facilities on neighbours. There has been a total failure for RM S [Roads \& Maritime Services] to be "controlled" in its planning development. [22, ID 7]

Aggrieved by public health recommendations, individuals stressed regulation for systemic change. "If exposure and impact reduction is to be acted upon, merely telling people to stay indoors on high air pollution days is only one element that is currently used. There needs to be a system for curtailing large air pollution sources from being operated" [22, ID7].

\subsection{Industry $(n=6)$}

The Australian Institute of Petroleum (AIP), Maritime Industry A ustralia, $L$ td. (MIAL), Royal Caribbean Cruise Lines (RCCL) and Genesee \& Wyoming (GW) freight railroad company commenced by documenting industry scope and their economic contribution to national/international economies. NSW Ports (NSWP) and Ports A ustralia (PA) defended their compliance with incoming federal fuel changes, with NSWP [22, p.1] requesting "industry self-monitoring with governmentfunded regional air quality monitoring". PA's agenda sought a laissez-faire regulatory approach, with shipping industries framed as subjects of regulatory inconsistency, inequity, and disadvantage. NSWP [22, p.1] asked regulation be:

Applied on a state-wide basis to the whole freight and logistics sector so as not to disadvantage any operator on the basis of location...NSW Ports has consistently argued that shipping is an international industry that is best regulated through IM 0 processes. Now that the IM 0 has agreed to proceed with further regulation of sulphur in fuel, it is no longer necessary for the NSW Government to set its own limits which were likely to be inconsistent with international requirements and impose unnecessary cost and technical complexity on the shipping industry.

GW [22, p.2] critiqued NSW EPA's prioritisation areas, air quality data/metrics, legislative/policy inconsistencies, and, like shipping, claimed disadvantage 
arguing the paper shows, "the greatest benefit to air quality would be through the proactive management of household wood fired heaters...that..."contributes $47 \%$ of annual PM2.5" in Sydney, and "up to $75 \%$ of particulate emissions in July each year"." The cruise industry applied an inequity frame. RCCL noted, "MARPOL requirements apply to all shipping" [22, p.2]. The government's agenda to target/disadvantage cruise ships in air pollution regulation enabled RCCL to apply an inoperability frame stating, "cruise shipping represents only $2 \%$ of the shipping industry in A ustralia and therefore measures that are applied solely to cruise shipping rather than all shipping do not provide sufficient justification for the required investment by the fuel supply industry to enable it to provide compliant fuel" [22, p.2].

All Industry submissions made air quality data/monitoring recommendations. None refuted the veracity of ship emissions' public health consequences. Health was absent from all except NSW P [22, p.1] who requested emission measures that are, "evidence-based to achieve a significant benefit in...human health outcomes" without elaboration. AIP [22, p.3-4] "acknowledges the contribution of emissions from the consumption and distribution of petroleum products to urban air quality and climate change", stating:

the major source of emissions from petroleum products are from the use of petroleum products in motor vehicles, shipping and equipment. The major pollutants are hydrocarbons, carbon monoxide, particulate matter $\left(\mathrm{PM}_{10}\right.$ and $\left.P M_{2.5}\right)$ and oxides of nitrogen $\left(\mathrm{NO}_{\mathrm{x}}\right)$ and carbon dioxide $\left(\mathrm{CO}_{2}\right)$.

Nevertheless, its agenda highlighted regulatory equity. "It is also critical that policy is enforced and applied appropriately to all sources of emissions..." No industry discussed preventative health. Industry framed pollution management as 'compliance'. Highlighting the inequitable costs of regulatory inconsistency, an agenda of competition framed priorities to avoid what AIP [22, p.8] labelled the "significant 'free-rider' issue" causing "competitive disadvantage" for compliant businesses.

AIP [22, p.3] implored the review to "identify further improvements to reduce the regulatory burden and improve the efficacy of the legislation" yet asserted, "no prima facie case [exists] for review of sulfur in petrol and significant evidence has been provided to demonstrate that there are no operability and minimal environmental benefits from any further changes to fuel standards". As such, medicine and industry shared desire to legislate inadequacies and inefficiencies. The petroleum industry, however, like the cruise industry, threatened A ustralian market inoperability as AIP [22, p.3] claimed, "Any further changes to fuel standards will threaten the viability of the Australian refining industry". MIAL [22, p.3] similarly used compliance framing to discourage A ustralian exceptionalism and inequity in air quality control, stating, "The shipping industry is committed to meeting its environmental obligations...As a global industry, it is critical that environmental issues are driven at an international rather than local level to be most effective". The shipping Industry's agenda framed themselves as leaders voluntarily opting into stronger global emissions standards, arguing local regulation would constitute unfair regulatory burden and cost, and claimed inequity if changes ensue "given the small contribution to NSW air quality made by shipping....and the recent significant progress" [22, p.3].

\subsection{Government $(n=3)$}

Three government submissions (Balmain Greens' Member of Parliament (MP), Lake Macquarie City Council (LMCC), Local Government NSW (LGNSW)) discussed shipping. MP submitted a community petition that, like Individual submissions, only discussed cruise ships in W hite Bay. A ir pollution was framed locally with residents' perceptions reiterating NIMBY issues/actions. MP's [22, p. 1] frame extended neither beyond his electorate, nor to environmental impact by recommending, "the only long-term solution to address...emissions is shore to ship power". It also showed no engagement with air pollution research:

the significant levels of toxic pollution emitted by cruise vessels burning sulphur fuel at the White Bay Cruise Terminal...is a significant source of air pollution for the surrounding area, with residents reporting health issues...We urge you to directly address this significant air pollution issue, and to take action to protect residents both of the area around White Bay, and the broader Sydney Harbour, from the health risk posed by cruise ship pollution.

Since American research [32] found an inverse relationship between air pollution awareness and poor air quality, and that respiratory disease experience increased perceived poor air quality or health risk, irrespective of 'actual' air quality, ship emission visibility may amplify negative perceptions. LGNSW [22, p.5] also discussed cruise ships in Sydney, regulatory inconsistency, and inequity from NSW Government's amendment of fuel regulation "in 2015 to reduce the sulfur content of fuel used by cruise ships in Sydney Harbour", seeking "best practice requirements for emissions management for marine diesel emissions including shipping, recreational boating and cruise ships". Maritime emissions were one of LGNSW's [22, p.7] two air quality priorities, "we urge immediate action on coal dust in rail corridors, and minimising non-road diesel emissions (in the marine context)".

LMCC [22, p.2], like Individual and Professional Body submissions, stressed that the high public health costs of air pollution was "the second highest environmental security risk facing the City and its residents", costing $\sim \$ 500 \mathrm{M}$ this past decade. LM CC [22, p.3] argued for metrics using an "exposure-based system, equitable for all citizens of NSW". It advocated data quality and collection relative to pollutant-proximity and using metrics unrelated to population density. Employing this frame exposed inequities between urban-regional NSW and state government 'agendas' favouring Sydney by avoiding sub-micrometre or ultrafine PM exceedance standards, despite Commonwealth review of their negative health impact. LMCC $[22$, p.6] noted air pollution exposure is "a significant public health hazard 
in NSW" and specified planning/policy actions. Evidencing 'inconsistencies' among Australian Government bodies that Industry identified and Australia's failure to curb air pollution described in Individual, Community, and Professional Body submissions, Government submission content echoed similar concerns and air pollution issues.

\section{Conclusions}

Content analysis of public submissions responding to the Clean Air for NSW Consultation Paper found 7 issue categories and 5 stakeholder-types. In-depth analysis of 'shipping' found consistency regarding air pollution issues that was framed differently by stakeholder-type. None were satisfied with existing air quality metrics, enforcement, or outcomes. Individuals and Government framed content around local issues (i.e. cruise boats in Sydney), illustrated varied scientific knowledge of air pollution, and advocated regulation is required to address inefficiencies and inadequacies. Industry remained silent, or agreed, about its contribution to air pollution, using 'compliance' or 'disadvantage' frames to refocus attention to diverse air pollution causes, discuss economic non-viability of change, or advocate self-regulation for global standards. Medicine was the only Professional Body type prioritising public health education/awareness raising.

Government mistrust, regulatory inequity, varied risk/exposure, and issue partiality comprised 3 latent categories stakeholders used to frame 'shipping' issues whilst agreeing 'clean air' is necessary. Research evidences disassociation exists between 'real' and 'perceived' health risks [11, 34], knowledge and action [35], and that experience of related illness and/or 'seeing' air pollution affects air quality awareness [38] which may not reflect scientific air pollution measures [32]. Since 'more' knowledge may not solve environmental issues [35-37], solutions beyond increasing awareness and demanding 'more' data are needed to improve Australia's air. Global increases in ambient air pollution and deaths in industrialised countries are known contributors to expansive public health costs and economic productivity losses that are avoidable with enforced air standards, hazardous fuel bans and clean energy initiatives surmounting vested interests [6]. Findings mirror international environmental health research [32] showing, despite near scientific consensus of air pollution's toxicity [7], actions fail to advocate reducing pollution levels below that causing human morbidity or mortality. It is time government expenditure on 'public awareness' promotion take a back seat to legislation given the popular public health recommendation to 'avoid air pollution' is an action impossible for so many.

\section{References}

1. E. Goffman, Frame A nalysis (B oston: Northeastern U niversity Press, 1974)

2. S. Reese, J. Commun. 57, 148 (2008)

3. C.A. B enowitz-Fredericks, K. Garcia, M. Massey Pediatr. Clin. N. A m. 59, 693 (2012)

4. E. Einsiede, B. Thorne, Public responses to uncertainty Communicating Uncertainty (M awah: L awrence Erlbaum A ssociates, Inc, 1999)

5. T.J. Sullivan, C.T. Driscoll, C.M . B eier Environ. Sci. Policy 84, 69 (2018)

6. P.J. Landrigan, Lancet 2, 4 (2017)

7. B. B runekreef, Procedia 5, 6661 (2010)

8. B. Cunningham, M.A. Cunningham, B.W. Saigo, Environmental Science (B oston: M CG raw Hill, 2005)

9. National Environmental Protection Council. Proposed variation to the National Environment Protection (Ambient Air Quality) Measure standards for ozone, nitrogen dioxide and sulfur dioxide. (Commonwealth of A ustralia, 2019)

10. M. Gemmer, X. Bo, Adv. Clim. Change Res. 4, 50 (2014)

11. B. Dobbie, D. Green Environ. Res. Lett. 10, 055001 (2015)

12. R.A. Broome, M.E. Cope, B. Goldsworthy, 2016 Environ. Int. 87, 85 (2016)

13. J.J. Winebrake, J.J. Corbett, E.H. Green, Environ. Sci. Technol. 43, 4776 (2009)

14. M.L. Bell, K. Ebisu, K 2012 Environ. Health Perspect. 120, 1599 (2012)

15. M.L. M iranda, S.E. Edwards, M.H. K eating, Int. J. Environ. Res. Public Health 8, 1755 (2011)

16. Realestate.com. Real estate, property and homes for sale (REA Group L td, 2019)

17. NSW EPA. Clean Air for NSW. (NSW EPA, 2019)

18. NSW Port Authority. Annual Report Port Authority of New South Wales 2017/2018. (Port A uthority of New South Wales, 2018).

19. A ustralian Federal Government. National Clean Air Agreement 2019. (A ustralian Federal Government, 2019)

20. M. Sofiev, J.J. Winebrake, L. Johansson, 2018 Nature Comm. 9, 406 (2018)

21. Office of Environment \& Heritage. Clean Air for NSW Consultation Paper. (Office of Environment and Heritage, 2016)

22. NSW EPA. Clean Air for NSW Consultation. (NSW Environment Protection A gency, 2019)

23. K. K rippendorff, Content Analysis (Sage, 2018)

24. B. Saunders, J. Sim, T. Kingstone, Qual. Quant. 52, $1893(2018)$

25. C. Urquhart, Grounded Theory for Qualitative Research (Sage, 2013) 
26. E.R. Babbie, The Basics of Social Research (C engage Learning, 2010)

27. D.F. Polit, C.T. Beck Nursing Research (Lippincott Williams \& Wilkins, 2012)

28. M.E. McCombs, S.I. Ghanem The convergence of agenda setting and framing Framing Public Life (: Lawrence Erlbaum A Ssoc, 2001)

29. A.T. Ragusa, A. Chan, A. Crampton A Inf. Commun. Soc. 12, 678 (2009)

30. A. Crampton, A. Ragusa, Rural Society 18, 202 (2008)

31. P. Groves, A.T. Ragusa J Health Saf. Environ. 35, 49 (2019)

32. T.G. Reames, M.A. Bravo, Environ. Int. 122, 244 (2019)
33. A.T. Ragusa, A. Crampton, A m. J. Health Educ. 50, 176 (2019)

34. G. Wachinger, O. Renn, C. Begg, Risk A nal. 33, 1049 (2013)

35. A. Kollmuss, A. Agyeman, Eviron. Edu. Res. 8, 239 (2002)

36. A.B. Unal, L. Steg, M. Gorsira, Environ. Behav. 50, 1092 (2018)

37. S. Clayton, C. Manning, K. Krygsman, M. Speiser Mental Health and Our Changing Climate (American Psychological Association and ecoA merica, 2017)

38. N.P. Hyslop, A tmos. Environ. 43, 182 (2009) 